\title{
KAJIAN BIAYA PENGGANTIAN INVESTASI PEMANFAATAN LAHAN HUTAN DALAM RANGKA PENGELOLAAN SAMPAH RAMAH LINGKUNGAN: Studi Kasus Nambo
}

\author{
(Study of Replacement Cost of Investment for Forest Land Use in the Context of Sustainable \\ Waste Management: Nambo Case Study)
}

\author{
Setiasih Irawanti, Ismatul Hakim, Dian Charity Hidayat \& Dewi Ratna Kurniasari \\ Pusat Penelitian Sosial, Ekonomi, Kebijakan dan Perubahan Iklim, \\ Jl. Gunung Batu No. 5 Bogor, 16118, Indonesia \\ E-mail: s_irawanti@yahoo.com; ismatulhakim@yahoo.com; dian.charity@gmail.com; \\ dewiratna_sahidi@yahoo.com
}

Diterima 19 September 2016, direvisi 19 Mei 2017, disetujui 5 Juni 2017

\begin{abstract}
The high dependence of the community on forest resources led the state forest areas in Java managed by Perhutani to apply Community Based Forest Management approach (Pengelolaan Hutan Bersama Masyarakat) programme. In this programme, forest farmers become the member of Forest Village Community Institution (Lembaga Masyarakat Desa Hutan) to carry out upland rice and maize intercropping. Production forest area in the village of Nambo and Lulut are categorized as the class of pine bussines that produce gondorukem, turpentine, and timber, as well as upland rice and maize from intercropping. Utilization of 40 ha forest area for the processing and final waste area (TPPAS) in Nambo area for 35 years must be required to pay replacement cost of investment due to the opportunity loss to invest in pine plantations and intercropping businesses. The replacement cost is calculated by using the loss opportunity of interest (LOI) method. The resuts are shown that the replacement cost for pine plant investment of Perhutani amounted to Rp5,492,318,000 and the replacement cost for upland rice and corn crops investment of LMDH members amounted to Rp798,947,520.
\end{abstract}

Keywords: Pine; intercropping; waste; replacement cost of investment; loss opportunity of interest.

\begin{abstract}
ABSTRAK
Tingginya ketergantungan masyarakat kepada sumber daya hutan menyebabkan kawasan hutan negara di Jawa yang dikelola oleh Perhutani menerapkan pendekatan Pengelolaan Hutan Bersama Masyarakat (PHBM), masyarakat penggarap menjadi anggota Lembaga Masyarakat Desa Hutan (LMDH) untuk melakukan kegiatan tumpangsari tanaman padi gogo dan jagung. Kawasan hutan produksi di Desa Nambo dan Lulut adalah kelas perusahaan pinus yang menghasilkan gondorukem, terpentin, dan kayu, serta padi gogo dan jagung dari hasil tanaman tumpangsari. Pemanfaatan lahan hutan seluas 40 ha untuk tempat pemrosesan dan pengelolaan akhir sampah (TPPAS) Regional Nambo selama 35 tahun wajib membayar biaya penggantian investasi dikarenakan hilangnya kesempatan untuk berinvestasi bisnis tanaman pinus dan tanaman tumpangsari yang dihitung menggunakan metode loss opportunity of interest (LOI). Hasil analisis menunjukkan bahwa biaya penggantian investasi tanaman pinus bagi Perhutani sebesar Rp5.492.318.000 dan penggantian investasi tanaman padi gogo dan jagung bagi anggota LMDH sebesar Rp798.947.520.
\end{abstract}

Kata kunci: Pinus; tumpangsari; sampah; biaya penggantian nilai investasi; loss opportunity of interest. 


\section{PENDAHULUAN}

Luas daratan pulau Jawa hanya 6\% dari luas wilayah Indonesia namun harus menampung aktivitas $60 \%$ penduduk Indonesia sehingga terjadi penciutan kawasan hutan akibat peningkatan jumlah penduduk (Irawanti, 2009). Menurut Direktur Bina Perhutanan Sosial, Kementerian Lingkungan Hidup dan Kehutanan (KLHK), sekitar 7.960 .800 jiwa penduduk miskin tinggal di sekitar hutan (Ferri, 2015). Terkait besarnya ketergantungan masyarakat tersebut, kawasan hutan negara di pulau Jawa yang dikelola oleh Perhutani sebagian menerapkan pendekatan Pengelolaan Hutan Bersama Masyarakat (PHBM) yang memadukan aspek ekonomi, sosial, dan ekologi.

Menurut Keputusan Direksi Perum Perhutani Nomor 268/KPTS/DIR/2007 Tentang Pedoman Pengelolaan Sumber Daya HutanBersama MasyarakatPlus (PHBMPlus), PHBM Plus adalah suatu sistem pengelolaan sumber daya hutan dengan pola kolaborasi yang bersinergi antara Perum Perhutani dan masyarakat desa hutan atau para pihak yang berkepentingan dalam upaya mencapai keberlanjutan fungsi dan manfaat sumber daya hutan yang optimal dan peningkatan Indeks Pembangunan Manusia (IPM) yang bersifat fleksibel, partisipatif dan akomodatif. Dokumen keputusan tersebut juga mengatur bahwa di dalam implementasi PHBM, pelaku utama kegiatan kehutanan adalah penduduk desa hutan yang tergabung dalam Lembaga Masyarakat Desa Hutan (LMDH), dimana seluruh kegiatan persemaian, penanaman, pemeliharaan, dan pemanenan tanaman Perhutani dikerjasamakan dengan LMDH. Salah satu bentuk kerja sama antara Perhutani dengan LMDH adalah pembuatan tanaman tumpangsari.

Banyak studi telah menyebutkan bahwa pada waktu yang sama, peningkatan jumlah penduduk di beberapa daerah perkotaan yang pesat juga telah meningkatkan jumlah timbulan sampah. Putri (2014) menyebutkan bahwa di Kota Semarang peningkatan jumlah penduduk setiap tahunnya diiringi dengan jumlah sampah yang dihasilkan. Hal ini dipertegas oleh Desmonda (2011) di Surabaya, bahwa semakin bertambahnya jumlah penduduk maka otomatis aktivitas yang dilakukan oleh penduduk akan menimbulkan jumlah sampah yang semakin banyak. Januar (2003) menyebutkan bahwa peningkatan taraf hidup penduduk di Kota Malang seiring dengan meningkatnya kegiatan produksi dan konsumsi, menimbulkan permasalahan yaitu dihasilkannya sampah.

Menurut Sunarya (2016), peningkatan volume sampah akan menjadi permasalahan jika tidak diimbangi oleh upaya penanggulangannya. Kebutuhan Tempat Pengolahan dan Pemrosesan Akhir Sampah (TPPAS) yang ramah lingkungan mendesak untuk direalisasikan agar dapat memberi pelayanan kepada masyarakat perkotaan, memberi manfaat bagi masyarakat yang tinggal di sekitar lokasi, dan memperpanjang umur teknis TPPAS. Sesuai Surat Persetujuan Menteri Kehutanan Nomor S.272/MenhutVII/2013 Tentang Persetujuan Penggunaan Kawasan Hutan untuk Pembangunan Tempat Pengolahan dan Pemrosesan Akhir Sampah Regional Nambo seluas 40 ha di Kabupaten Bogor, Provinsi Jawa Baratmelaluimekanisme kerja sama dengan Perum Perhutani tanggal 19 April 2013, TPPAS Regional Nambo direncanakan berlokasi di hutan produksi yang termasuk kelas perusahaan pinus di Kesatuan Pengelolaan Hutan (KPH) Bogor.

Pemanfaatan lahan hutan yang dikelola oleh Perhutani untuk pembangunan TPPAS Regional Nambo wajib membayar kompensasi ekonomi atas hilangnya kesempatan untuk berinvestasi di lahan tersebut. Kelas perusahaan pinus menghasilkan getah pinus yang disadap sejak tanaman berumur 11 tahun sampai akhir daur, dan saat dilakukan penebangan akhir akan dihasilkan kayu. Getah pinus diolah lebih lanjut menjadi gondorukem dan terpentin. Di samping itu, pemanfaatan lahan hutan untuk pembangunan 
TPPAS Regional Nambo juga menyebabkan hilangnya kesempatan penggarap atau anggota LMDH untuk melakukan kegiatan tumpangsari. Terkait hal tersebut, tulisan ini menginformasikan hasil analisis biaya penggantian investasi tanaman pinus yang menghasilkan gondorukem, terpentin, dan kayu oleh Perhutani, serta hasil analisis biaya penggantian investasi tumpangsari padi gogo dan jagung oleh anggota LMDH. Pada akhirnya, hasil perhitungan dari kajian ini dapat menjadi dasar penentuan besarnya kompensasi yang wajar dan adil bagi para pemangku kepentingan.

\section{METODE PENELITIAN}

\section{A. Lokasi Penelitian}

Penelitian ini dilakukan di hutan produksi yang merupakan kelas perusahaan pinus seluas 40 ha di blok hutan Cibedil, kelompok hutan Gunung Karang, Resort Pemangkuan Hutan (RPH) Gunung Karang, Bagian Kesatuan Pemangkuan Hutan (BKPH) Jonggol, KPH Bogor, atau di wilayah Desa Nambo dan Desa Lulut Kecamatan Klapanunggal Kabupaten Bogor. Lahan hutan tersebut dialokasikan untuk pembangunan TPPAS Regional Nambo. Pengumpulan data penelitian dilakukan mulai Oktober 2014 sampai dengan Oktober 2015.

\section{B. Metode Pengumpulan Data}

\section{Pengamatan lapangan}

Pengamatan lapangan bertujuan mengetahui kondisi lapangan calon lokasi TPPAS Regional Nambo, meliputi jenis vegetasi yang tumbuh di lokasi tersebut, jarak dari lokasi pemukiman, dan interaksi penduduk sekitar.

\section{Konsultasi dan wawancara}

Konsultasi kepada jajaran Pemerintah Provinsi Jawa Barat dan Perhutani Divisi Regional (Divre) Jawa Barat terkait perhitungan penggantian nilai investasi tanaman pinus serta tanaman tumpangsari padi gogo dan jagung atas pemanfaatannya untuk pembangunan TPPAS Regional Nambo.
Studi literatur dilakukan untuk menelusuri metode analisis yang sesuai, serta wawancara untuk mengumpulkan data jenis-jenis produk, volume produksi, harga, pendapatan, biaya, rendemen, dan data pendukung yang terkait.

Konsultasi ke Perum Perhutani KPH Bogor untuk mengetahui status dan jumlah petani penggarap pada kawasan hutan seluas 40 ha. Konsultasi kepada kepala desa untuk mengetahui sosial budaya masyarakat sekitar kawasan hutan tersebut. Data untuk keperluan perhitungan penggantian nilai investasi bagi anggota LMDH juga dikumpulkan dari beberapa sumber seperti Laporan Dinas Pertanian dan Kehutanan Kabupaten Bogor, Laporan dari KPH Bogor, serta referensi dan pustaka.

\section{Analisis Data}

Lahan hutan Perhutani merupakan sektor riil yang memiliki nilai tambah ekonomis karena selama ini telah ditanami pohon pinus. Dengan demikian, apabila akan digunakan untuk pembangunan TPPAS Regional Nambo dalam jangka waktu 35 tahun maka kompensasi wajib diberikan. Kompensasi atas penggunaan sumber daya alam tersebut disebut juga sewa sumber daya (resource rents) yang merupakan opportunity cost atas berkurangnya sumber daya yang telah digunakan dan hasil dari memaksimalkan present value profit (Arnason, 2008). Menurut Alchian dalam Arnason (2008) sewa sumber daya diformulasikan sebagai berikut :

$$
R(q, x)=D(q) \cdot q=\Pi q(q, x) \cdot q
$$

$\mathrm{D}(\mathrm{q})=$ permintaan sumber daya

$\pi \quad=$ profit

$\mathrm{q}=$ kuantitas

Di samping itu, menurut Marshall (Duccio, 2013) interest adalah harga yang harus dibayar untuk penggunaan barang modal di pasar manapun. Oleh karena itu, dalam hal penggantian biaya investasi pada kasus ini digunakan istilah interest sebagai pengganti permintaan sumber daya. 
Tegakan pohon dan biaya yang digunakan untuk menghasilkan tanaman baru merupakan investasi yang besarnya berbeda- beda sesuai dengan jenis tanaman (Evija, 2010). Guna menghitung pertumbuhan investasi pada tegakan tersebut, digunakan formula sebagai berikut:

$$
\mathrm{V}_{\mathrm{n}}=\mathrm{V} 0(1+\mathrm{r})^{\mathrm{n}}
$$

$\mathrm{V}_{\mathrm{n}}=$ pengembalian investasi yang sudah didiskonto/return with interest

$\mathrm{V}_{0}=$ jumlah investasi

$\mathrm{r}=$ discount rate yang besarnya sesuai dengan jenis tegakan / tanaman.

$\mathrm{n}=$ tahun

Rumus tersebut senada dengan formula future value untuk menghitung nilai uang di masa yang akan datang.

Terkait dengan penggantian nilai investasi atas pemanfaatan lahan hutan untuk pembangunan TPPAS Regional Nambo, waktu pembayaran kompensasi penting dalam perhitungan karena berhubungan dengan time value of money. Menurut Sutrisno dalam Winarno (2014) terdapat dua konsep nilai waktu uang, yaitu nilai yang akan datang (future value) dan nilai sekarang (present value). Apabila pembayaran biaya penggantian investasi dilakukan secara angsuran atau setelah tahun pertama pembangunan TPPAS, maka discount rate harus diperhitungkan untuk menggantikan ketidakpastian di masa yang akan datang (premium of uncertainty) (Damodaran, 2010). Dengan kata lain, future value harus digunakan dalam perhitungan jika pembayaran dilakukan setelah tahun pertama. Namun apabila semua pembayaran biaya penggantian investasi dilakukan pada tahun ke-0 atau sebelum pembangunan TPPAS dimulai, maka penggantian biaya investasi dibayarkan menggunakan profit yang dihitung berdasarkan data historis atas total keuntungan selama 35 tahun yang diperoleh pada saat ini dengan memperhitungkan future value pada tahun ke- 0 sehingga rumusnya menjadi:

$$
\begin{aligned}
\mathrm{V}_{\mathrm{n}} & =\mathrm{Vo}(1+\mathrm{r})^{0} \\
\mathrm{~V}_{\mathrm{n}} & =\mathrm{V} 0
\end{aligned}
$$

Vn tersebut yang kemudian dinamakan Loss Opportunity of Interest (LOI).

1. Pada perhitungan biaya penggantian investasi untuk pengusahaan tanaman pinus, LOI merupakan nilai keuntungan kumulatif sampai akhir daur.

\section{Keuntungan $=$ Total Penerimaan - Total Biaya}

dimana:

- Total Penerimaan $=$ Jumlah produksi (gondorukem + terpentin + kayu) x Harga rata-rata (RKAP, 2013)

- Total Biaya = Biaya-biaya tanam, pemeliharaan, penyadapan, penebangan, pengolahan getah.

Perhitungan dilakukan menggunakan table cash flow dalam bentuk excel selama 35 tahun yaitu sejak tahun pertama penanaman bibit pinus sampai dengan tebang akhir pada umur tanaman pinus 35 tahun.

2. Perhitungan penggantian biaya investasi bagi penggarap atau anggota LMDH didekati dengan nilai hasil panen tanaman tumpangsari padi gogo dan jagung selama 2 tahun yang dihitung dengan rumus sederhana sebagai berikut:

$\mathrm{NT}_{\text {tot }}=\mathrm{Nt}_{1}+\mathrm{Nt}_{2}$

$\left.\left.\mathrm{Nt}_{1}=\sum\left(\left(\mathrm{P}_{\mathrm{i} 1} \mathrm{x} \mathrm{H}_{\mathrm{i} 1}\right)-\mathrm{B}_{\mathrm{i} 1}\right)\right)+\sum\left(\left(\mathrm{P}_{\mathrm{j} 1} \mathrm{xH}_{\mathrm{j} 1}\right)-\mathrm{Bj} 1\right)\right)$

\begin{tabular}{|c|c|}
\hline $\mathrm{NT}_{\text {tot }}$ & $=$ Nilai tanaman pangan total $(\mathrm{Rp})$ \\
\hline $\mathrm{Nt}_{1}$ & $\begin{aligned}= & \text { Nilai tanaman pangan tahun ke- } 1 \\
& (\mathrm{Rp})\end{aligned}$ \\
\hline$t_{2}$ & $\begin{array}{l}\text { Nilai tanaman pangan tahun ke-2 } \\
\text { (Rp) }\end{array}$ \\
\hline & $\begin{array}{l}\text { Produktivitas gabah kering giling } \\
\text { (GKG) (ton/tahun) }\end{array}$ \\
\hline & Harga GKG (Rp/kg) \\
\hline & Biaya GKG (Rp/tahun) \\
\hline & $\begin{array}{l}\text { Produktivitas jagung kering pipil } \\
\text { (JKP) (ton/tahun) }\end{array}$ \\
\hline & Harga JKP $(\mathrm{Rp} / \mathrm{kg})$ \\
\hline & Biaya JKP (Rp/tahun) \\
\hline
\end{tabular}

dimana: 


\section{HASIL DAN PEMBAHASAN}

Gambaran lokasi TPPAS Regional Nambo Lahan seluas 40 ha yang dialokasikan untuk pembangunan TPPAS Regional Nambo merupakan bagian dari lahan seluas 221,80 ha hasil tukar-menukar lahan yang dilakukan pada tahun 1973 antara pemerintah dengan PT Semen Gresik yang sekarang menjadi PT Indosemen. Lokasi Desa Nambo Kecamatan Klapanunggal ditetapkan sebagai Tempat Pembuangan Akhir (TPA) Regional melalui Keputusan Bupati Bogor Nomor 591/315/Kpts/Huk/2002 Tentang Penetapan Lokasi TPA di Desa Nambo Kecamatan Klapanunggal.

Pada tahun 2004, melalui kegiatan Detail Engineering Design (DED) dengan luasan studi 15 ha di lokasi TPPAS Regional Nambo, dicapai kesepakatan aspek manajemen dan finansial antara Kabupaten Bogor, Kota Bogor dan Kota Depok bahwa TPPAS Regional Nambo ditetapkan sebagai TPA Terpadu. Dalam Surat Bupati Bogor Nomor 658.1/371DCK tanggal 30 Oktober 2003 dinyatakan bahwa operasional dan pemeliharaan TPPAS Regional Nambo dilaksanakan bersama diantara tiga pemerintah kota/kabupaten, dan pembiayaan investasi pembangunan sarana prasarana TPA yang cukup besar diusulkan ke Anggaran Pendapatan dan Belanja Daerah (APBD) Provinsi Jawa Barat dan/atau Departemen Pekerjaan Umum. Lokasi TPPAS Nambo juga telah sesuai dengan Rencana Tata Ruang Wilayah (RTRW) Kabupaten Bogor dan Rencana Pembangunan Jangka Menengah (RPJM) Pemerintah Provinsi Jawa Barat.

Surat Persetujuan Menteri Kehutanan Nomor S.272/Menhut-VII/2013 Tanggal 19 April 2013 menyatakan bahwa lokasi kerja sama TPPAS Regional Nambo adalah di hutan produksi kelas perusahaan pinus, blok hutan Cibedil, kelompok hutan Gunung Karang, RPH Gunung Karang, BKPH Jonggol, KPH Bogor, atau di wilayah Desa Nambo dan Desa Lulut Kecamatan Klapanunggal Kabupaten
Bogor, dengan luas areal kerja sama 40 ha serta maksimal jangka waktu kerja sama adalah 5 tahun dan dapat diperpanjang. Dalam hal ini pengelolaan TPPAS Regional Nambo dilakukan dengan pendekatan kerja sama antara Pemerintah Provinsi Jawa Barat dan Perum Perhutani (Gubernur Jawa Barat dan Kepala Perhutani Divre Jawa Barat dan Banten, 2014). Demikian pula menurut Peraturan Menteri Keuangan Nomor 96/ PMK.06/2007 Tentang Tata Cara Pelaksanaan Penggunaan, Pemanfaatan, Penghapusan dan Pemindahtanganan Barang Milik Negara (BMN) bahwa pemanfaatan BMN dapat dilakukan dalam bentuk sewa, pinjam pakai, kerja sama pemanfaatan, serta bangun guna serah dan bangun serah guna. Barang Milik Negara dimaksud dapat berupa tanah dan/ atau bangunan serta selain tanah dan/atau bangunan, dimana jangka waktu kerja sama pemanfaatan BMN paling lama 30 (tiga puluh) tahun sejak ditandatanganinya perjanjian, dan dapat diperpanjang.

TPPAS Regional Nambo mempunyai kewajiban untuk melakukan reklamasi dan rehabilitasi, sehingga dari total luas areal 55 ha yang berasal dari lahan hutan Perhutani seluas 40 ha dan dari lahan Pemerintah Daerah (Pemda) Kabupaten Bogor seluas 15 ha, sekitar 30\% nya atau 15 ha akan dibangun ruang terbuka hijau (RTH) dengan harapan bahwa proses pengelolaan sampah lebih ramah lingkungan.

\section{B. Teknologi Pengolahan Sampah Terpadu}

Pembangunan TPPAS Nambo berkapasitas 9.000 ton sampah/hari diharapkan dapat segera terwujud sebagai solusi permasalahan sampah di Kota Depok, Kota Bogor dan Kabupaten Bogor. Menurut Rahmawati (2016), produksi sampah dari Kabupaten Bogor, Kota Bogor dan Kota Depok saat ini sekitar 1.500 ton sampah/hari, sehingga membutuhkan kapasitas TPA yang sangat besar. Berat 1 truk sampah adalah 3 ton, sehingga ada 500 truk sampah per hari masuk ke TPPAS Regional Nambo. 
Sampah akan diolah menggunakan teknologi modern yang membutuhkan investasi cukup besar. Pengolahan sampah terpadu meliputi tahapan (1) pemilahan sampah, (2) pengelolaan sampah (sanitary landfill, insinerasi, pengomposan, anaerobic digestion, biodrying).

\section{Pemilahan sampah}

Pemilahan akan memisahkan sampah berdasarkan unsur-unsur tertentu yang akan diolah pada tahapan selanjutnya. Pemilahan dapat dilakukan secara manual, semi mekanik, dan full mekanik.

\section{Pengelolaan sampah}

Pengelolaan sampah dapat dilakukan dengan berbagai metode, diantaranya dengan cara sanitary landfill, insinerasi, pengomposan, anaerobic digestion, biodrying (Diskimrum Jawa Barat, 2013).

a. Sanitary landfill merupakan pembuangan akhir sampah di suatu area terbuka skala besar secara "sehat" atau saniter, tidak mencemari lingkungan misalnya dengan memberi lapisan kedap air pada dasar landfill, membuat saluran air lindi, pemipaan gas dan penutupan dengan lapisan tanah secara regular (Wahyono, 2001). Sampah ditimbun merata secara berlapis, dipadatkan dan ditutup tanah atau material lain pada setiap akhir hari operasi. Metode ini biasa digunakan oleh TPA pada umumnya karena relatif mudah dan murah namun berpotensi menimbulkan masalah lingkungan (Wahyono, 2001), karena limbah organik akan didekomposisi oleh mikroba dalam tanah menjadi senyawa gas dan cair. Bila senyawa ini berinteraksi dengan air yang dikandung oleh limbah dan air hujan maka akan membentuk bahan cair yang disebut lindi (leachate) yang dapat mencemari tanah.

b. Insinerasi adalah proses pembakaran sampah secara terkendali menjadi gas dan abu, dimana gas dilepaskan ke udara sedangkan abu dibuang ke TPA atau dicampur dengan bahan lain sehingga menghasilkan produk yang berguna.

c. Pengomposan adalah proses biologi yang dilakukan oleh mikroorganisme untuk mengubah limbah padat organik menjadi produk stabil menyerupai humus. Kompos dapat digunakan untuk menguatkan struktur lahan kritis, menggemburkan kembali tanah pertanian, menggemburkan kembali tanah pertamanan, sebagai bahan penutup sampah di TPA, reklamasi pasca penambangan, sebagai media tanaman, dan mengurangi penggunaan pupuk kimia. Pengomposan sampah organik dapat dilakukan pada skala rumah tangga, skala kawasan, dan skala besar.

d. Anaerobic Digestion (AD). Biogas adalah teknologi konversi biomassa (sampah) menjadi gas dengan bantuan mikroba anaerob. Teknologi yang sering digunakan untuk memanfaatkan biogas dari sampah organik adalah Anaerobic Digestion (AD). AD adalah proses biologis yang sering dimanfaatkan pada pengolahan air limbah untuk mendegradasi dan menstabilkan lumpur. Secara umum AD sudah lama digunakan di daerah perdesaan untuk memproduksi biogas yang dapat digunakan untuk memasak dan penerangan. Dalam skala besar sudah diterapkan di banyak negara maju di Eropa untuk mengelola sampah perkotaan sekaligus mendapatkan hasil samping biogas yang dimanfaatkan untuk penggerak generator listrik.

e. Biodrying adalah variasi dari dekomposisi aerobic digunakan dalam unit mechanical-biological treatment (MBT) untuk mengeringkan dan menstabilkan residu sampah. Mekanisme pengeringan yang utama adalah penguapan konvektif menggunakan panas dari biodegradasi aerobic sampah dan difasilitasi oleh aliran udara mekanis. Pada biodrying, kelembaban limbah dikurangi dari 35-35\% w/w menjadi $20-10 \%$ w/w. Unit biodrying MBT dapat menghasilkan refused derived 
fuel (RDF) yang berkualitas tinggi karena kandungan biomassanya tinggi.

\section{Pengolahan sampah}

Teknologi biodrying dipilih sebagai teknologi pengolahan sampah di TPPAS Regional Nambo karena proses ini menghasilkan volume residu relatif sedikit berupa batu, kaca, dan lain-lain, sehingga umur teknis TPPAS diharapkan lebih panjang atau dapat digunakan sepanjang masa. Refused derived fuel (RDF) merupakan alternatif pemanfaatan sampah menjadi energi pengganti bahan bakar fosil dan batubara. Komposisi sampah yang baik akan menghasilkan RDF dengan nilai kalori bakar 1,5 kali lebih tinggi dari batubara. RDF banyak diperlukan oleh instalasi pemanas, seperti tungku pembakaran, dalam industri. Berbagai industri memerlukan produk RDF yang lebih baik bentuknya daripada serbuk, sehingga dikembangkan RDF terpadatkan (Densified-RDF).

\section{Ruang Terbuka Hijau}

Teknologi pengolahan sampah yang digunakan di TPPAS Nambo adalah teknologi ramah lingkungan, tidak ada pencemaran dan tidak ada pemulung (RTS, 2017). Sebagian besar sampah diolah menggunakan proses aerobic menjadi sampah kering, tidak mengeluarkan gas metan, dan menghasilkan bahan bakar RDF untuk mensubstitusi batubara yang akan mengurangi emisi GRK. Sebagian lagi diolah menggunakan proses biologi untuk menghasilkan kompos.

Meskipun pembangunan TPPAS Nambo telah mengantongi Analisis Mengenai Dampak Lingkungan (AMDAL) dan Izin Lingkungan (RTS, 2017), namun keinginan untuk mewujudkan unit pengolahan sampah yang ramah lingkungan juga dilakukan dengan membangun RTH pada $30 \%$ dari luasan arealnya yang posisinya akan mengelilingi areal instalasi mesin-mesin pengolah sampah. RTH tersebut akan menjadi hamparan hijau yang berfungsi memperbaiki dan menjaga iklim mikro, meningkatkan nilai estetika, memasok daerah resapan air, serta menciptakan keseimbangan dan keserasian lingkungan fisik TPPAS. Secara visual RTH dapat berupa kawasan taman dan hutan kota, yang ada unsur pohon dan asosiasinya. Berbagai jenis pohon dapat ditanam di RTH dengan berbagai macam peran masing-masing jenis pohon dalam meminimalkan kerugian lingkungan, sebagai berikut (Samsoedin, Susidharmawan, Pratiwi, \& Wahyono, 2015)

1. Peredam kebisingan suara mesin-mesin pengolah sampah. Menurut (Grey \& Deneke, 1978) bahwa dedaunan tanaman dapat menyerap kebisingan sampai 95\%.

2. Penyerap karbon dioksida dan penghasil oksigen. Jenis tanaman yang baik sebagai penyerap gas $\mathrm{CO}_{2}$ dan penghasil oksigen yaitu damar (Agathis alba), daun kupukupu (Bauhinia purpurea), lamtoro gung (Leucaena leucocephala), akasia (Acacia auriculiformis) dan beringin (Ficus benjamina) (Widyastama,1991).

3. Penyerap dan penapis bau. Jenis flora yang dapat menghasilkan bau harum antara lain cempaka (Michelia champaka) dan tanjung (Mimusops elengi);

4. Penyerap dan penjerap partikel timbal yang mencemari udara di perkotaan yang bersumber dari kendaraan bermotor (Goldsmith \& Hexter, 1967). Diperkirakan sekitar $60-70 \%$ partikel timbal di udara perkotaan berasal dari kendaraan bermotor (Krishnayya \& Bedi, 1986). Dahlan (1989) menyatakan damar (Agathis alba), mahoni (Swietenia macrophylla), jamuju (Podocarpus imbricatus), pala (Myristica fragrans), asam landi (Pithecellobium dulce) dan johar (Cassia siamea) mempunyai kemampuan tinggi menurunkan kandungan timbal di udara. Beberapa tanaman berikut, glodogan (Polyalthia longifolia), keben (Barringtonia asiatica) dan tanjung (Mimusops elengi), walaupun kemampuan serapannya terhadap timbal rendah, namun tanaman tersebut tidak peka terhadap pencemar udara; 
5. Penyerap dan penjerap debu semen. Sejumlah tanaman dapat ditanam di RTH karena memiliki ketahanan tinggi terhadap pencemaran debu semen dan kemampuan tinggi dalam menjerap (adsorpsi) dan menyerap (absorpsi) debu semen, yaitu mahoni (Swietenia macrophylla), bisbul (Diospyros discolor), tanjung (Mimusops elengi), kenari (Canarium commune), meranti merah (Shorea leprosula), kere payung (Filicium decipiens), kayu hitam (Diospyros celebica), duwet (Eugenia cuminii), medang lilin (Litsea roxburghii) dan sempur (Dillenia ovata);

6. Penahan angin, dengan memperhatikan faktor-faktor sebagai berikut:

a. Jenis tanaman memiliki dahan kuat.

b. Daunnya tidak mudah gugur oleh terpaan angin dengan kecepatan 'sedang'.

c. Akarnya menghunjam masuk ke dalam tanah.

d. Memiliki kerapatan yang cukup (50$60 \%$ ).

e. Tinggi dan lebar jalur RTH cukup besar agar dapat melindungi wilayah yang diinginkan dengan baik.

RTH di TPPAS Nambo juga diharapkan dapat mewadahi kegiatan edukasi peningkatan wawasan masyarakat tentang pengelolaan dan pengolahan sampah ramah lingkungan.

\section{Biaya Penggantian Investasi Pemanfaatan Kawasan Hutan}

Berdasarkan Peraturan Menteri Lingkungan Hidup dan Kehutanan Nomor P.50/Menlhk/Setjen/Kum.1/6/2016 Tentang Pedoman Pinjam Pakai Kawasan Hutan, kegiatan pengelolaan sampah termasuk kegiatan bertujuan strategis dan non komersial yang dapat dilakukan melalui mekanisme kerja sama. Jangka waktu izin tersebut diberikan sesuai dengan jangka waktu penggunaan yang dalam hal ini adalah 35 tahun. Terkait hal tersebut, menurut Peraturan Menteri Kehutanan Nomor: P.18/
menhut-II/2011 Tentang Pedoman Pinjam Pakai Kawasan Hutan yang dimaksud dengan izin pinjam pakai kawasan hutan adalah izin yang diberikan untuk menggunakan kawasan hutan untuk kepentingan pembangunan di luar kegiatan kehutanan tanpa mengubah fungsi dan peruntukan kawasan hutan. Berdasarkan Peraturan Pemerintah Nomor 33 Tahun 2014 Tentang Jenis dan Tarif atas Jenis Penerimaan Negara Bukan Pajak (PNBP) yang Berasal dari Penggunaan Kawasan Hutan untuk Kepentingan Pembangunan di Luar Kegiatan Kehutanan yang Berlaku pada Kementerian Kehutanan, izin pinjam pakai yang bersifat non komersial dikenakan tarif PNBP nol rupiah

Pada perhitungan biaya penggantian investasi pemanfaatan lahan hutan, LOI merupakan nilai keuntungan kumulatif sampai akhir daur (tahun ke-35), biaya merupakan jumlahan seluruh biaya pembangunan, pemeliharaan, dan pemanenan getah dan kayu pinus sampai akhir daur (tahun ke-35) serta pengolahan getah menjadi gondorukem dan terpentin, dan penerimaan merupakan jumlahan seluruh penerimaan atas hasil gondorukem, terpentin dan kayu dari tahun ke-11 sampai akhir daur (tahun ke-35).

\section{Harga satuan berdasarkan standar harga Perum Perhutani}

Penghitungan LOI dilakukan menggunakan harga satuan yang ditetapkan sebagai standar harga atau biaya oleh Perum Perhutani (Tabel $1)$.

\section{Asumsi dan perhitungan}

Asumsi yang digunakan dalam penghitungan LOI mengacu pada beberapa sumber.

a. Sesuai Surat Keputusan (SK) Kepala Perum Perhutani Unit III Jawa Barat dan Banten Nomor 399/041.1/PP\&Bang-Ush/ III, 5 Agustus 2011 bahwa produktivitas getah pinus adalah 0,48 ton $/$ ha/th. Penyadapan getah pinus oleh Perhutani dimulai pada umur tanaman 11 tahun. 
Tabel 1. Standar harga satuan dari Perum Perhutani tahun 2014

Table 1. Standard of pricing unit of Perum Perhutani year 2014

\begin{tabular}{rlcr}
\hline No & Kegiatan (Activity) & Satuan (Unit) & \multicolumn{2}{c}{$\begin{array}{c}\text { Biaya (Cost) } \\
\text { (x Rp 1.000) }\end{array}$} \\
\hline 1 & Tanaman & $\mathrm{Rp} / \mathrm{ha}$ & 4.459 \\
\hline 2 & Pemeliharaan I & $\mathrm{Rp} / \mathrm{ha}$ & 2.264 \\
\hline 3 & Pemeliharaan II & $\mathrm{R} / \mathrm{ha}$ & 2.123 \\
\hline 4 & Pemeliharaan 4-5 th & $\mathrm{Rp} / \mathrm{ha}$ & 500 \\
\hline 5 & Sadapan & $\mathrm{Rp} / \mathrm{ton}$ & 4.000 \\
\hline 6 & Tebangan & $\mathrm{Rp} / \mathrm{m} 3$ & 300 \\
\hline 7 & Pengolahan getah & $\mathrm{Rp} / \mathrm{ton}$ & 3.000 \\
\hline 8 & Harga gondorukem & $\mathrm{Rp} / \mathrm{ton}$ & 29.930 \\
\hline 9 & Harga terpentin & $\mathrm{Rp} / \mathrm{ton}$ & 35.700 \\
\hline 10 & Harga kayu pinus & $\mathrm{Rp} / \mathrm{m}^{3}$ & 900 \\
\hline
\end{tabular}

Sumber (Source): Perum Perhutani

Tabel 2. Asumsi dalam perhitungan biaya penggantian investasi di TPPS Nambo tahun 2014

Table 2. The assumptions in the calculation of replacement cost of investment at TPPS Nambo year 2014

\begin{tabular}{|c|c|c|c|}
\hline Kegiatan (Activity) & $\begin{array}{c}\text { Satuan } \\
\text { (Unit) }\end{array}$ & $\begin{array}{l}\text { Jumlah } \\
\text { (Amount) }\end{array}$ & Keterangan (Remarks) \\
\hline Luas tanaman & ha & 28 & Luas efektif tegakan $70 \%=28$ ha \\
\hline Luas pemeliharaan I & ha & 28 & \\
\hline Luas pemeliharaan II & ha & 28 & \\
\hline $\begin{array}{l}\text { Luas pemeliharaan } \\
4-5 \text { th }\end{array}$ & ha & 28 & \\
\hline Luas sadapan & ha & 28 & \\
\hline Produksi getah & ton/ha/th & 0,48 & $\begin{array}{l}\text { Sesuai SK Kepala Perum Perhutani Unit III Jabar } \\
\text { Banten Nomor 399/041.1/PP\&Bang-Ush/III, } 5 \text { Agustus } \\
\text { 2011. Sadap getah Perhutani mulai tahun ke-11 }\end{array}$ \\
\hline Pengolahan getah & ton/th & 13,44 & \\
\hline Tebangan & ha & 28 & \\
\hline $\begin{array}{l}\text { Produksi kayu } \\
\text { glondongan }\end{array}$ & $\mathrm{m}^{3}$ & $2.916,48$ & $\begin{array}{l}\text { Produksi kayu sbb: } \\
\text { - Kayu pinus umur } 35 \text { th pada bonita II } \\
\text { - Volume produksi } 254 \mathrm{~m}^{3} / \mathrm{ha} \text { (normal) } \\
\text { - } \text { Penjarangan } 37 \mathrm{~m}^{3} / \mathrm{ha} \\
\text { - Sisa produksi }(254-37) \mathrm{m}^{3} / \mathrm{ha}=217 \mathrm{~m}^{3} / \mathrm{ha} \\
\text { - Volume produki dengan faktor koreksi kenormalan } \\
0,8=0,8(217)=173,6 \mathrm{~m}^{3} / \mathrm{ha} \\
\text { - Volume produksi dengan faktor koreksi kowakan } 0,6 \\
=0,6(173,6)=104,16 \mathrm{~m}^{3} / \mathrm{ha}\end{array}$ \\
\hline Produksi gondorukem & Ton/th & 9,0048 & Rendemen $67 \%$ \\
\hline Produksi terpentin & Ton/th & 2,1504 & Rendemen $10 \%$ \\
\hline
\end{tabular}

Sumber (Source): Perum Perhutani 
b. Berdasarkan Peraturan Menteri Lingkungan Hidup dan Kehutanan Nomor P.12/Menlhk-II/2015 Tentang Pembangunan Hutan Tanaman Industri, areal tanaman pokok paling banyak $70 \%$ dari areal kerja.

c. Perhitungan produksi kayu glondongan pinus, rendemen produksi gondorukem dan terpentin mengacu pada hasilhasil penelitian Badan Penelitian, Pengembanngan dan Inovasi.

\section{Hasil perhitungan biaya pengganti investasi}

Perhitungan keuntungan kumulatif selama 35 tahun yang dilakukan menggunakan datadata dalam Tabel 1 dan Tabel 2 diperoleh hasil sebagaimana disajikan dalam Tabel 3. Semua pembayaran biaya penggantian investasi dilakukan pada tahun ke-0 yaitu sebelum pembangunan TPPAS dimulai, sehingga penggantian biaya investasi dibayarkan menggunakan profit kumulatif yang dihitung berdasarkan data historis atas total keuntungan selama 35 tahun yang diperoleh pada saat ini. Oleh karena itu, perhitungan tersebut tidak menggunakan discount factor.

Nilai keuntungan kumulatif sampai akhir daur (35 tahun) adalah sebesar Rp5.492.318.000 dengan Net Present Value (NPV) positif sebesar Rp225.960.2000 dan Internal Rate of Return (IRR) sebesar 11\%, yang mengindikasikan bahwa keuntungan kumulatif tersebut layak secara finansial. Nilai keuntungan kumulatif tersebut digunakan sebagai dasar untuk menetapkan besarnya biaya penggantian investasi bagi Perhutani atas hilangnya kesempatan untuk melakukan investasi usaha hutan tanaman pinus di kawasan hutan yang dimanfaatkan sebagai TPPAS Regional Nambo dengan asumsi pembayaran dilakukan pada tahun ke-0. Apabila pembayaran dilakukan secara bertahap maka akan diperhitungkan future value. Dengan demikian besarnya biaya penggantian investasi bagi Perhutani adalah sebesar Rp5.492.318.000.

Berdasarkan Peraturan Nomor P.50/ Menlhk/Setjen/Kum.1/6/2016 Tentang Pedoman Pinjam Pakai Kawasan Hutan, kegiatan pengelolaan sampah termasuk kegiatan bertujuan strategis dan non komersial yang dapat dilakukan melalui mekanisme kerja sama dan sesuai Peraturan Pemerintah Nomor 33 Tahun 2014 Tentang Jenis dan Tarif atas Jenis Penerimaan Negara Bukan Pajak yang Berasal dari Penggunaan Kawasan Hutan untuk Kepentingan Pembangunan di Luar Kegiatan Kehutanan yang Berlaku pada Kementerian Kehutanan, maka izin pinjam pakai yang bersifat non komersial ini dikenakan tarif PNBP nol rupiah.

\section{E. Biaya Penggantian Investasi Bagi Anggota LMDH}

Tumpangsari merupakan salah satu teknik penanaman hutan yang dilakukan oleh Perhutani dimana penggarap dapat menggarap lahan, serta menanam padi gogo dan tanaman pangan lainnya diantara baris-baris tanaman

Tabel 3. Hasil perhitungan biaya penggantian investasi kawasan hutan di TPPS Nambo Table 3. Calculation result of compensation cost of investment for forest area at TPPS Nambo

\begin{tabular}{lc}
\hline \multicolumn{1}{c}{ Uraian (Clarification) } & $\begin{array}{c}\text { Jumlah (Amount) } \\
(\mathrm{Rp})\end{array}$ \\
\hline Pengeluaran & 6.578 .760 .000 \\
\hline Pendapatan & 12.071 .078 .000 \\
\hline Keuntungan & 5.492 .318 .000 \\
$\bullet$ Keuntungan dari getah & 2.492 .510 .000 \\
\hline
\end{tabular}

Sumber (Source): Data diolah 
pokok. Menurut Riajaya \& Kadarwati (2005), produksi tanaman tumpangsari merupakan fungsi dari pengelolaan budidaya dan lingkungan yang menyangkut interaksi antara tanah dan iklim mikro di sekitar tanaman. Riajaya \& Kadarwati (2005) juga menyebutkan bahwa pada sistem tumpangsari terjadi interaksi yang sangat kompleks antara dua tanaman atau lebih dalam penggunaan air, cahaya dan hara. Kegiatan tumpangsari umumnya dilakukan selama dua tahun sejak penanaman bibit tanaman pokok kehutanan dengan pertimbangan tanaman pokok kehutanan belum menaungi tanaman pangan. Penggarap mempunyai tanggung jawab memelihara tanaman pokok kehutanan, dan mendapat imbalan berupa uang kontrak dan seluruh hasil panen tanaman pangan atau tanaman semusim. Tanaman pokok kehutanan dapat berupa tanaman jati, pinus, rimba (mahoni, mangium, dan lain-lain) sehingga ada kelas perusahaan jati, kelas perusahaan pinus, kelas perusahaan rimba. Menurut Peraturan Pemerintah Republik Indonesia Nomor 6 Tahun 2007 Tentang Tata Hutan dan Penyusunan Rencana Pengelolaan Hutan, serta Pemanfaatan Hutan, Kementerian Kehutanan memberikan akses kepada masyarakat setempat untuk memanfaatkan kawasan hutan dalam pemberdayaan masyarakat setempat dengan melaksanakan (a) tumpangsari pada awal penanaman (tiga tahun pertama), (b) tumpangsari di bawah tegakan (sepanjang waktu), (c) tanaman kehidupan pada Hutan Tanaman Industri (HTI) (5\% dari luas HTI), dan (d) tumpang gilir pada HTI.

Tumpangsari merupakan salah satu teknik agroforestry yaitu teknologi budidaya yang mengkombinasikan tanaman pertanian dan kehutanan dalam rangka optimalisasi penggunaan lahan (Yuwariah, 2015), dan bermanfaat untuk menciptakan peluang dan meningkatkan potensi bagi kesejahteraan manusia serta pelestarian sumber daya alam sebagai pendukung pertanian berkelanjutan (Sumarwoto, 2012). Bentuk agroforestry sederhana yang paling banyak dijumpai di
Jawa adalah tumpangsari yang dikembangkan dalam rangka program perhutanan sosial dari Perum Perhutani. Petani diberi izin menanam tanaman pangan diantara pohon-pohon jati muda dan hasilnya untuk petani, sedangkan semua pohon jati tetap menjadi milik Perhutani (Dirjen RLPS, 2008).

Di sekitar wilayah kerja RPH Gunung Karang, BKPH Jonggol dimana TPPAS akan dibuat, terdapat tujuh desa dengan jumlah anggota Lembaga Masyarakat Desa Hutan (LMDH) sebanyak 203 orang. Diantara desa tersebut, Desa Lulut dan Desa Nambo merupakan desa-desa yang berdekatan dengan lokasi TPPAS Regional Nambo. Di Desa Lulut terdapat 30 orang anggota LMDH dan di Desa Nambo terdapat 35 anggota LMDH. LMDH di kedua desa tersebut didirikan pada tahun 2008, sudah mempunyai lembaga yang berbadan hukum dan bekerja di Hutan Pangkuan Desa (HPD).

\section{Dasar perhitungan}

\section{a. Asumsi}

- Lahan hutan ditanami pinus dan tanaman tumpangsari padi dan jagung, tidak ada tanaman lain yang dimasukan dalam perhitungan ini.

- Tanaman tumpangsari dilakukan pada dua tahun pertama penanaman bibit pinus.

- Volume dan nilai produksi tahun pertama dan tahun kedua adalah sama.

- Luas garapan sesuai standar Perhutani adalah 0,25 ha per penggarap, semua kegiatan pengusahaan tanaman tumpangsari dikerjakan oleh tenaga kerja keluarga, upah tenaga kerja (HOK) dibayarkan oleh penggarap kepada keluarganya sendiri, upah menjadi bagian dari nilai produksi bersih.

\section{b. Data primer dari Dinas Pertanian dan Kehutanan Bogor, 2015}

- Produktivitas tanaman padi gogo 2,982 ton/ha (gabah kering giling), tanaman 
jagung 4,778 ton/ha (jagung kering pipil) (Laporan Dinas Pertanian dan Kehutanan Kabupaten Bogor, 2015).

- Harga jual padi Rp5.000/kg (gabah kering giling), jagung Rp3.150/kg (jagung kering pipil) (Laporan Dinas Pertanian dan Kehutanan Kabupaten Bogor, 2015)

- Jumlah Hari Orang Kerja (HOK) tanaman padi gogo $150 \mathrm{HOK} / \mathrm{ha}$, jagung 195 HOK/ha (Laporan Dinas Pertanian dan Kehutanan Kabupaten Bogor, 2015)

- Tarif upah pekerja Rp40.000/HOK (Laporan Dinas Pertanian dan Kehutanan Kabupaten Bogor, 2015)

- Biaya sarana produksi tanaman padi Rp1.537.500/ha, tanaman jagung Rp4.645.000/ha (Laporan Dinas Pertanian dan Kehutanan Kabupaten Bogor, 2015).

\section{Data primer dari Perhutani KPH Bogor}

- Luas tanaman tumpangsari $60 \%$ dari luas tanaman pinus $(70 \%)$ atau setara dengan $42 \%$ dari luas lahan 40 ha, yaitu 16,8 ha.

- Dalam satu tahun dilakukan panen jagung dan panen padi masing-masing satu kali.

\section{Penghitungan nilai produksi tanaman tumpangsari}

Perhitungan nilai produksi tanaman tumpangsari dilakukan menggunakan asumsi pada butir (a) serta data primer pada butir (b) dan (c) sehingga diperoleh hasil sebagaimana disajikan dalam Tabel 4.

Besarnya nilai produksi bersih tanaman tumpangsari padi gogo dan jagung adalah Rp798.947.520. Nilai produksi bersih tersebut digunakan sebagai dasar untuk menetapkan besarnya biaya penggantian investasi atas hilangnya nilai harapan penggarap atau anggota LMDH untuk melakukan kegiatan tumpangsari di kawasan hutan yang dimanfaatkan sebagai TPPAS Regional Nambo dalam kerangka kerja sama antara Pemerintah Provinsi Jawa Barat dan Perum Perhutani. Dengan demikian besarnya biaya penggantian investasi bagi anggota LMDH atau penggarap adalah Rp798.947.520, dimana nilai tersebut belum termasuk pajak.

\section{KESIMPULAN DAN SARAN}

\section{A. Kesimpulan}

Kawasan hutan produksi di Desa Nambo dan Desa Lulut merupakan kelas perusahaan pinus yang menghasilkan getah pinus yang diolah lebih lanjut menjadi gondorukem dan terpentin serta menghasilkan kayu yang dipanen pada akhir daur. Kelas perusahaan pinus dikelola menggunakan pendekatan PHBM sehingga ada LMDH yang anggotanya melakukan kegiatan tumpangsari tanaman padi gogo dan jagung.

Biaya penggantian investasi bagi Perhutani atas hilangnya kesempatan untuk melakukan

Tabel 4. Nilai hasil panen padi gogo dan jagung

Table 4. Harvest result value of rice and corn

\begin{tabular}{cllr}
\hline No. (No.) & \multicolumn{1}{c}{ Uraian (Clarification) } & Perhitungan (Calculation) & Jumlah (Amount) \\
\hline 1 & Nilai produksi (Rp/ha) & $14.910 .000+15.050 .700$ & 29.960 .700 \\
\hline 2 & Biaya saprodi (Rp/ha) & $1.537 .500+4.645 .000$ & 6.182 .500 \\
\hline 3 & Upah tenaga kerja (Rp/ha) & $6.000 .000+7.800 .000$ & 13.800 .000 \\
\hline 4 & Nilai produksi bersih (Rp/ha) & 23.778 .200 \\
\hline 5 & Nilai produksi bersih luas 16,8 ha (Rp) & 399.473 .760 \\
\hline 6 & Nilai produksi bersih dua tahun tanam $(\mathrm{Rp})$ & 798.947 .520 \\
\hline
\end{tabular}

Sumber (Source): Data diolah 
investasi usaha hutan tanaman pinus di kawasan hutan yang dimanfaatkan sebagai TPPAS Regional Nambo adalah sebesar Rp5.492.318.000. Semua pembayaran biaya penggantian investasi tersebut dilakukan pada tahun ke-0 yaitu sebelum pembangunan TPPAS dimulai, sehingga penggantian biaya investasi dibayarkan menggunakan profit kumulatif yang dihitung berdasarkan data historis atas total keuntungan selama 35 tahun yang diperoleh pada saat ini, sehingga perhitungan tersebut tidak menggunakan discount factor.

Biaya penggantian investasi bagi anggota LMDH ditetapkan berdasarkan hasil perhitungan nilai produksi bersih tanaman tumpangsari padi gogo dan jagung selama dua tahun yaitu sebesar Rp798.947.520. Teknologi biodrying dipilih sebagai teknologi pengolahan sampah di TPPAS Regional Nambo, proses ini menghasilkan volume residu relatif sedikit berupa batu, kaca, dan lain-lain, sehingga umur teknis TPPAS diharapkan lebih panjang atau dapat digunakan sepanjang masa.

\section{B. Saran}

Pengelolaan sampah di TPPAS Regional Nambo menggunakan teknologi biodrying, volume residu relatif sedikit dan umur teknis TPPAS lebih panjang, serta sebagian areal dibangun hutan kota untuk merehabilitasi lahan kritis, menciptakan lingkungan yang asri dan nyaman, dan meredam polusi, sehingga TPPAS Regional Nambo dapat menjadi model pengelolaan sampah ramah lingkungan.

Memperhatikan Pasal 23 Peraturan Menteri Lingkungan Hidup dan Kehutanan Nomor P.50/Menlhk/Setjen/Kum.1/6/2016 Tentang Pedoman Pinjam Pakai Kawasan Hutan, maka metode loss opportunity of interest (LOI) dapat digunakan untuk menghitung penggantian biaya investasi pemanfaatan kawasan hutan untuk berbagai kepentingan pembangunan di luar kegiatan kehutanan.

\section{UCAPAN TERIMA KASIH (ACKNOWLEDGEMENT)}

Ucapan terimakasih disampaikan kepada Dinas Pemukiman dan Perumahan Pemerintah Provinsi Jawa Barat yang telah membiayai kegiatan ini. Publikasi ini merupakan bagian dari Laporan Hasil Kajian Nilai Penggantian Investasi Tanaman Pinus dan Laporan Hasil Kajian Nilai Tanaman Tumpangsari, dalam kerangka kerja sama Pengelolaan TPPAS Regional pada Kawasan Hutan Perhutani dengan Pemerintah Provinsi Jawa Barat yang dilaksanakan tahun 2014-2016.

\section{DAFTAR PUSTAKA}

Arnason, R. (2008). Natural resource rents : Theoretical clarification. Institute of Economic Studies Working Papers, W08:07 (December). Retrieved September 18, 2016 from http:// www.ioes.hi.is

Dahlan, E. (1989). Studi kemampuan tanaman dalam menjerap dan menyerap timbal emisi dari kendaraan bermotor. Bogor: Institut Pertanian Bogor.

Damodaran, A. (2010). Applied corporate finance (3rd ed.). New York: John Wiley \& Sons.

Desmonda, N. I. (2011). Bertambahnya sampah akibat pertambahanpendudukdiSurabaya. Retrieved May 9, 2017 from http://www.kompasiana. com/nicoirjaya92/bertambahnya-sampahakibat-pertambahan-penduduk-disurabaya_550b637e813311f813b1e5d7.

Dinas Pertanian dan Kehutanan Kabupaten Bogor. (2015). Laporan Dinas Pertanian dan Kehutanan Kabupaten Bogor. Bogor: Dinas Pertanian dan Kehutanan Kabupaten Bogor.

Dirjen RLPS. (2008). Penanganan krisis sumber daya lahan dan pemanfaatan kawasan hutan untuk pengadaan pangan. Prosiding Semiloka Nasional: Strategi penanganan krisis sumber daya lahan untuk mendukung kedaulatan pangan dan energi, 22-23 Desember 2008. Bogor: Departemen Ilmu Tanah dan Sumber Daya Lahan, Fakultas Pertanian Institut Pertanian Bogor.

Diskimrum Jawa Barat. (2013). Revisi detail engineering design pengelolaan TPPAS Regional Nambo. (Laporan Akhir). Bandung: PT Maza Pradita Sarana.. 
Duccio, C. (2013). Alfred marshall on the theory of capital. MPRA Paper, (35423), 601-626. http://doi.org/10.5897/JAERD12.088

Evija, G.-S. (2010). Application of discount rate in forestry. Forest Sciences, 170-175.

Ferri, R. (2015, June 11). Kemenhut baru realisasikan 157.617 ha hutan masyarakat. Jogja. tribunnews.com.

Goldsmith, J. R., \& Hexter, A. C. (1967). Respiratory exposure to lead: Epidemiological and experimental dose-response relationship. Science, 158, 132-134.

Grey, G. W., \& Deneke, F. I. (1978). Urban forestry. New York: John Wiley and Sons.

Gubernur Jawa Barat dan Kepala Perhutani Divre Jawa Barat dan Banten. (2014). Perjanjian Kerja Sama antara Pemerintah Provinsi Jawa Barat dengan Perum Perhutani Divisi Regional Jawa Barat dan Banten Nomor 658.1/97/ Otdakasm-04/PKS/Divreg-Janten/2014 Tentang Penggunaan Kawasan Hutan untuk Tempat Pembuangan Akhir (TPA) dan Pengelolaan.

Irawanti, S. (2009). Kelembagaan kerja sama pada program PHBM dalam praktek pengelolaan hutan. In G. B. Aji, J. Suryanto, T. I. Miranda, S. Irawanti, B. Soepijanto, A. Karyana, ... S. Simanjuntak (Eds.), Social forestry di Indonesia: Kolaborasi pengelolaan sumber daya hutan. Jakarta: Ditjen Rehabilitasi Lahan dan Perhutanan Sosial Departemen Kehutanan \& Wicaksana Megacipta.

Januar, M. A. (2003). Peningkatan teknis operasional pengelolaan sampah di Kota Malang. Semarang: Universitas Diponegoro.

Keputusan Bupati Bogor Nomor 591/315/Kpts/ Huk/2002 Tentang Penetapan Lokasi TPA di Desa Nambo Kecamatan Klapanunggal.

Keputusan Direksi Perum Perhutani Nomor: 268/KPTS/DIR/2007 tentang Pedoman Pengelolaan Sumber Daya Hutan Bersama Masyarakat Plus (PHBM Plus).

Krishnayya, N. S. R., \& Bedi. (1986). An Effect of automobile lead pollution on Cassia tora and C. occidentalis L. Environmental Pollution (Series A), 40(3), 221-226.

Peraturan Menteri Kehutanan Nomor P.18/MenhutII/2011 Tentang Pedoman Pinjam Pakai Kawasan Hutan.

Peraturan Menteri Keuangan Nomor 96/PMK.06/2007
Tentang Tata Cara Pelaksanaan Penggunaan, Pemanfaatan, Penghapusan Dan Pemindahtanganan Barang Milik Negara.

Peraturan Menteri Lingkungan Hidup dan Kehutanan Nomor : P.12/Menlhk-II/2015 Tentang Pembangunan Hutan Tanaman Industri.

Peraturan Menteri Lingkungan Hidup Nomor P.50/ Menlhk/Setjen/Kum.1/6/2016 Tentang Pedoman Pinjam Pakai Kawasan Hutan.

Peraturan Pemerintah Nomor 33 Tahun 2014 Tentang Jenis dan Tarif atas Jenis Penerimaan Negara Bukan Pajak yang Berasal dari Penggunaan Kawasan Hutan untuk Kepentingan Pembangunan di Luar Kegiatan Kehutanan yang Berlaku pada Kementerian Kehutanan.

Peraturan Pemerintah Republik Indonesia Nomor 6 Tahun 2007 Tentang Tata Hutan dan Penyusunan Rencana Pengelolaan Hutan, serta Pemanfaatan Hutan.

Putri, A. (2014). Potensi dan strategi pengembangan green business masyarakat sebagai kontribusi dalam pengelolaan sampah berkelanjutan di kota Semarang. Semarang: Universitas Diponegoro.

Rahmawati, L. (2016, Januari 31). Pemkot Bogor desak tempat penampungan sampah Nambo segera beroperasi. Antaranews.com.

Riajaya, P. D., \& Kadarwati, F. T. (2005). Pengaruh kerapatan tanam galur harapan kapas terhadap sistem tumpangsari dengan jagung. LITTRI, 11(2), 67-72.

RTS. (2017, March 6). Konsorsium Korea di Nambo. Kompas, p. 26.

Samsoedin, I., Susidharmawan, I. W., Pratiwi, \& Wahyono, D. (2015). Peran pohon dalam menjaga kualitas udara di perkotaan. (1st ed.). Bogor: Forda Press.

Sumarwoto. (2012). Budidaya iles-iles kuning untuk kesejahteraan masyarakat. In Budiadi, D. P. Permadi, \& L. P. Umi (Eds.). Agroforestry Porong, masa depan hutan Jawa, Indonesia managing higher education for relevance and efficiency (IMHERE). Yogyakarta: Fakultas Pertanian UGM.

Sunarya. (2016). Penentuan rute pengambilan sampah menggunakan metode nearest neighbour di PD. Kebersihan Kota Bandung untuk kapasitas kendaraan $10 \mathrm{~m}^{3}$ dengan daerah pelayanan Bandung Selatan dan Bandung Timur. Bandung: Universitas Pasundan. 
Surat Persetujuan Menteri Kehutanan Nomor S.272/ Menhut-VII/2013 Tentang Persetujuan Penggunaan Kawasan Hutan untuk Pembangunan TPAS Regional Nambo seluas 40 ha di Kabupaten Bogor Provinsi Jawa Barat melalui Mekanisme Kerja Sama dengan Perum Perhutani.

Wahyono, S. (2001). Pengolahan sampah organik dan aspek sanitasi. Jurnal Teknologi Lingkungan, 2(2), 113-118.
Widyastama, R. (1991, Juli 11). Jenis Tanaman berpotensi untuk penghijauan kota. Kompas.

Winarno, S. H. (2014). Analisis penilaian keputusan investasi menggunakan metode net present value. Moneter, I(1).

Yuwariah, Y. (2015, November). Potensi agroforestry untuk meningkatkan pendapatan kemandirian bangsa, dan perbaikan lingkungan. Seminar Nasional Agroforestry 2015, Bale Sawala. Jatinangor: Universitas Padjajaran. 